\title{
The time course of age-of-acquisition effects on eye movements during reading: Evidence from survival analyses
}

\author{
Barbara J. Juhasz ${ }^{1} \cdot$ Heather Sheridan ${ }^{2}$ \\ Published online: 5 July 2019 \\ (C) The Psychonomic Society, Inc. 2019
}

\begin{abstract}
Adults process words that are rated as being learned earlier in life faster than words that are rated as being acquired later in life. This age-of-acquisition (AoA) effect has been observed in a variety of word-recognition tasks when word frequency is controlled. AoA has also previously been found to influence fixation durations when words are embedded into sentences and eye movements are recorded. However, the time course of AoA effects during reading has been inconsistent across studies. The current study further explored the time course of AoA effects on distributions of first-fixation durations during reading. Early and late acquired words were embedded into matched neutral sentence frames. Participants read the sentences while their eye movements were recorded. AoA effects were observed in both early and late fixation duration measures, suggesting that AoA has an early and long-lasting effect on word-recognition processes during reading. Survival analysis revealed that the earliest discernable effect of AoA on distributions of first-fixation durations emerged beginning at $158 \mathrm{~ms}$. This rapid influence of AoA was confirmed through the use of Vincentile plots, which demonstrated that the effect of AoA occurred early and was relatively consistent across the distribution of fixations. This pattern of results provides support for the direct lexical-control hypothesis, as well as the viewpoint that AoA may exert an influence at multiple loci within the mental lexicon.
\end{abstract}

Keywords Age of acquisition · Fixation durations $\cdot$ Eye movements $\cdot$ Distributional analysis $\cdot$ Time course $\cdot$ Lexical processing $\cdot$ Reading

Reading entails a sophisticated coordination of oculomotor control and ongoing lexical processing. In order to accurately process letters within a word, a saccade must be programmed to bring text into the fovea, where visual acuity is greatest. How this coordination is accomplished has been debated in the eye-movement literature (see, e.g., Reingold, Reichle, Glaholt, \& Sheridan, 2012, for discussion). One issue concerns the role that lexical variables play in directly controlling saccadic planning. Although it's well-known that lexical variables can influence mean fixation duration measures (for a review, see Rayner, 2009), the time course of this influence has been a topic of longstanding controversy among models of eye-movement control during reading. Given this controversy,

Barbara J. Juhasz

bjuhasz@wesleyan.edu

1 Department of Psychology, Wesleyan University, Middletown, CT, USA

2 Department of Psychology, University at Albany, State University of New York, Albany, NY, USA the present study examined the time course of the age-ofacquisition (AoA) variable using distributional analyses of fixation durations. Accordingly, we will begin by briefly reviewing prior work that used distributional analyses to study eye-movement control during reading, and we will then outline our theoretical rationale for using distributional analyses to examine the age-of-acquisition variable.

Models of eye-movement control during reading have adopted dramatically different assumptions about the time course of lexical influences on fixation durations (for a review of this controversy, see Reingold, Sheridan, \& Reichle, 2015). Some models assume that lexical and linguistic aspects of a fixated word can rapidly affect both short and long fixation durations (i.e., the direct lexical-control hypothesis), whereas other models assume that fixation durations are largely driven by visual/oculomotor factors, with lexical and linguistic aspects of a word only impacting a small subset of long fixation durations. Support for the rapid impact of lexical variables on fixations durations has recently been obtained using distributional analyses, including survival analyses, Vincentile analyses, and ex-Gaussian analyses. Distributional analyses provide additional information about 
the impact of experimental variables on fixation durations (or reaction times) that cannot be obtained from means and variance alone. This is because the same size of mean effect can reflect either a change in the shape (i.e., skew) of the distribution, and/or a shift in the distributions (see, e.g., Balota \& Yap, 2011). Of relevance to the present paper, survival analyses can be used to estimate the earliest discernable effect of lexical variables on distributions of fixations (see Reingold et al., 2012; Reingold \& Sheridan, 2014, 2018). Survival curves are calculated by determining the proportion of "surviving" fixations (i.e., fixations that have not yet been terminated by a saccade) as a function of time. Specifically, the survival percentage for a given time, $t$, is equal to the percentage of fixations with a duration greater than $t$. Survival analyses can be used to estimate the divergence point, which is the point at which the survival curves from two different conditions first begin to show a discernable difference. Research using survival analyses has shown that lexical variables (e.g., word frequency, predictability, lexical ambiguity) produce an early effect on distributions of fixations that emerges within the range of approximately $110 \mathrm{~ms}$ to $150 \mathrm{~ms}$ after fixation onset (for a review, see Reingold et al., 2015), which is in line with exGaussian analyses showing that lexical variables can produce a shift effect (e.g., Reingold et al., 2012; Sheridan \& Reingold, 2012a, 2012b; Staub, 2011; Staub, White, Drieghe, Hollway, \& Rayner, 2010), as well as evidence that lexical variables can have a rapid influence on neurophysiological measures (for a review, see, e.g., Reichle \& Reingold, 2013).

However, prior work has not yet documented the impact of age-of-acquisition (AoA) on distributions of fixations during reading. Words that are learned earlier in childhood are processed faster into adulthood. Since AoA effects are correlated with other lexical variables, including word frequency, some researchers have questioned whether AoA represents a separate and distinct construct (see Zevin \& Seidenberg, 2004). In support of the independent role of AoA, word-recognition research has demonstrated the influence of this variable when optimal measures of word frequency are accounted for (e.g., Brysbaert \& Cortese, 2011). Moreover, as summarized in Table 1, the distinct influence of AoA has also been supported by the handful of eye-movement studies exploring AoA effects during reading (Cushman \& Johnson, 2011; Dirix \& Duyck, 2017a, 2017b; Juhasz, 2018; Juhasz \& Rayner, 2003, 2006).

While each study reported in Table 1 has demonstrated an effect of AoA on mean fixation durations during reading, the time course has varied. Typically, four fixation duration measures are explored. First-fixation duration is the duration of the initial fixation on a word, and it is considered to be an index of early lexical processing. Single fixation duration is also a measure of the initial fixation, but only when the word receives one fixation during a reader's first pass through the sentence. In this case, it is likely that the reader has fully identified the word prior to moving his or her eyes to the next word. Gaze duration is the sum of fixations on the word before the reader moves his or her eyes to the next word. This summed measure again likely reflects full lexical access. Finally, total fixation durations also include rereading the word. This is therefore considered to be a late measure of processing that also incorporates integrative processes.

The studies included in Table 1 have explored AoA effects on the eye-movement record by contrasting different target words that varied in adult ratings of when they were acquired. The eye-movement studies of Juhasz, Gullick, and Shesler (2011) and Joseph, Wonnacott, Forbes, and Nation (2014) took different approaches to studying the mechanisms behind AoA effects in reading. Juhasz et al. (2011) embedded balanced ambiguous words with two equally frequent meanings (e.g., straw) into sentences where the prior context disambiguated their meaning. Critically, the two meanings of the balanced ambiguous words differed in their rated meaning AoA. First-fixation durations, gaze durations, and total fixation durations were significantly shorter when the preceding context supported the early acquired meaning, suggesting that AoA may affect access to semantic representations during reading. Joseph et al. (2014) recorded adults' eye movements as they were exposed to new vocabulary items over 5 days. Early items were introduced on Day 1, and late items were introduced on Day 2. Total fixation durations were longer on the late items when they were read in neutral sentences after training. Performance on a memory test was also significantly higher for the early items. These results suggest that the AoA effect on fixation durations may be attributable to the order with which words are first learned.

Although AoA effects on word recognition have been shown using a variety of tasks (for reviews, see Johnston \& Barry, 2006; Juhasz, 2005), there is still debate as to the locus of the AoA effects. Briefly, the semantic locus theory ascribes AoA effects to the organization of the semantic representations of words. This is supported by research observing AoA effects in semantic categorization tasks (e.g., Ghyselinck, Custers, \& Brysbaert, 2004) as well as the work of Steyvers and Tenenbaum (2005), who observed that early learned concepts became semantic hubs in their model of a growing semantic network. This single-locus account can be contrasted with the network plasticity hypothesis that was derived from the connectionist modeling work of Ellis and Lambon Ralph (2000). They observed that items entered early into training were learned better by the network due to greater plasticity. With respect to word recognition, if later learned words are simply not learned as effectively, then AoA should have multiple loci during lexical processing. Specifically, AoA should influence all aspects of word recognition, including access to orthography, phonology, and semantics.

Juhasz and Rayner (2003; Juhasz, 2018) have argued that the time course of AoA effects on the eye-movement record 
Table 1 Eye-movement studies exploring AoA effects during reading

\begin{tabular}{|c|c|c|c|c|c|c|c|}
\hline Study & Analysis type & Participants & Sample size & $\mathrm{FF}$ & $\mathrm{SF}$ & GD & TT \\
\hline \multirow[t]{2}{*}{ Juhasz \& Rayner (2003) } & Regression & Younger adults & 40 & $\dagger$ & $*$ & $*$ & $\dagger$ \\
\hline & Regression & Younger adults ${ }^{a}$ & 40 & n.s. & $*$ & n.s. & n.s. \\
\hline \multirow[t]{2}{*}{ Juhasz \& Rayner (2006) } & Factorial & Younger adults & 32 & $9 \mathrm{~ms}^{*}$ & $10 \mathrm{~ms}^{*}$ & $20 \mathrm{~ms}^{*}$ & $26 \mathrm{~ms}^{*}$ \\
\hline & Factorial & Younger adults ${ }^{b}$ & 40 & $15 \mathrm{~ms}^{*}$ & $17 \mathrm{~ms}^{*}$ & $21 \mathrm{~ms}^{*}$ & $23 \mathrm{~ms} \dagger$ \\
\hline \multirow[t]{2}{*}{ Cushman \& Johnson (2011) } & Factorial & Individual with pure alexia ${ }^{c}$ & 1 & NA & NA & NA & $2,263 \mathrm{~ms}^{*}$ \\
\hline & Factorial & Older adults & 6 & NA & NA & $41 \mathrm{~ms}^{*}$ & $43 \mathrm{~ms} \dagger$ \\
\hline Dirix \& Duyck (2017a) & Regression & Younger adults $^{\mathrm{d}}$ & 14 & $10 \mathrm{~ms}^{*}$ & $14 \mathrm{~ms}^{*}$ & $21 \mathrm{~ms}^{*}$ & $36 \mathrm{~ms}^{*}$ \\
\hline Dirix \& Duyck (2017b) & Regression & Younger adults ${ }^{\mathrm{e}}$ & 19 & $*$ & n.s. & $*$ & $*$ \\
\hline Juhasz (2018) & Regression & Younger adults ${ }^{\mathrm{f}}$ & 45 & $\dagger$ & $\dagger$ & $*$ & $*$ \\
\hline
\end{tabular}

Note. $* p<.05 . \dagger p<.10$. n.s. $=$ not statistically significant; NA = not assessed; $\mathrm{ms}=$ milliseconds.

${ }^{a}$ The second analysis included a measure of cumulative frequency derived from The Educator's Word Frequency Guide (Zeno, Ivens, Hillard, \& Duvvuri, 1995).

${ }^{\mathrm{b}}$ This factorial analysis is a subset of the items used in Juhasz and Rayner (2003).

${ }^{\mathrm{c}}$ The paired item data are reported.

${ }^{\mathrm{d}}$ Native speakers of English reading an English novel. Estimates of the size of the effect are from median splits of the AoA variable.

${ }^{\mathrm{e}}$ Native Dutch speakers reading a novel in Dutch. Results for L1 AoA are reported.

${ }^{\mathrm{f}}$ All items were bilexemic English compound words

supports a semantic locus to the effect, as the AoA effect was strongest in the fixation duration measures such as single fixation duration and gaze duration in those studies, where semantic processing was presumably completed. However, differentiating between the network plasticity account and the semantic locus account of AoA effects is difficult in silent reading, since access to orthographic word forms, phonological word forms, and semantic representations all presumably occur during a single fixation on a word. In addition, as Dirix and Duyck (2017a, 2017b) have suggested, the two theories of AoA effects are not mutually exclusive, and AoA effects in reading may be explained by a combination of both greater overall plasticity for learning early acquired items as well as faster access to semantic representations.

One of the main goals for the current study was to examine the eye-movement record for evidence for the network plasticity hypothesis of AoA effects. If early learned items are encoded better due to greater plasticity early in reading development, then we would expect AoA to affect multiple loci, including the early lexical processing that precedes access to a word's meaning (e.g., the processing of orthographic and phonological word forms). This multiple loci perspective implies that AoA effects may emerge rapidly enough to affect the duration of the very first fixation on a word. Also, this perspective implies that AoA would have a rapid effect on distributions of first-fixation durations, which would indicate that AoA effects on mean first-fixation durations are not solely being driven by a subset of long fixations. Alternatively, if AoA affects mean fixation durations, but does not emerge rapidly enough to influence first-fixation durations, then this pattern of results could suggest that the AoA effect is limited to semantic processing, as hypothesized by a single locus account of AoA effects.

A possible theoretical framework for understanding the present study's time-course predictions is provided by the EZ Reader model of eye-movement control (e.g., Reichle, Pollatsek, \& Rayner, 2012), which assumes that the ongoing lexical processing of words is the mechanism that moves the eyes forward during reading. According to this model, lexical processing is serial (i.e., one word is processed at a time) and consists of two different stages: An initial $L_{1}$ stage that has been linked to orthographic and phonological processing (and may also reflect a rapid sense that a word is familiar), and a subsequent $L_{2}$ stage that has been linked to semantic processing (and also constitutes the completion of lexical access). The completion of $L_{1}$ triggers the planning of a saccade to the next word, and the subsequent completion of $L_{2}$ triggers a shift in attention to the next word. Of relevance to the present study's prediction that lexical variables, such as AoA, can rapidly affect eye-movement control, the $L_{1}$ stage of word processing in the E-Z Reader model is hypothesized to be affected by both word frequency and predictability. Moreover, research using event-related potentials (ERPs) has demonstrated rapid influences of a variety of lexical variables, including Reichle, Tokowicz, Liu, and Perfetti's (2011) demonstration of a robust influence of word frequency in a time interval from $173 \mathrm{~ms}$ to $141 \mathrm{~ms}$ prior to saccade onset to the next word. This time frame is consistent with the hypothesized $L_{1}$ stage of lexical processing and is also consistent with the rapid lexical effects on fixation distributions that were discussed above (for a review, see Reingold et al., 2015). The question for the current research project is whether AoA will also be found to have a rapid 
influence on first-fixation durations and therefore could plausibly affect an early stage of lexical processing as conceptualized, for example, by the $L_{1}$ stage in the E-Z Reader model.

Given the importance of time course information to the development of both models of word recognition and models of eye-movement control during reading, our study explored the time course of AoA effects on fixation distributions. Words that were rated as early and late acquired were embedded into counterbalanced sentence frames, and eye movements were recorded while participants silently read the sentences. These early and late items were matched on an optimal measure of word frequency (SUBTLEX-US; Brysbaert \& New, 2009) as well as other relevant lexical and semantic variables in order to provide a strong test of AoA effects (see Table 2). We first wished to replicate past eye-movement studies in showing an effect of AoA on mean fixation durations. To provide a test of the network plasticity hypothesis of AoA effects, we were especially interested in establishing the impact of AoA on first-fixation durations using a larger number of items and participants than in past eye-movement studies. In addition to exploring the mean AoA effect on fixation durations, as has been done in past studies, we also used survival and Vincentile analyses to examine the time course of AoA effects on distributions of fixations for the first time.

\section{Method}

\section{Participants}

Forty-seven Wesleyan University undergraduates participated in this experiment. They received partial credit for their

Table 2 Item characteristics

\begin{tabular}{lll}
\hline & Early AoA & Late AoA \\
\hline Rated AoA & $2.80(.42)$ & $4.75(.61)^{* * *}$ \\
Kuperman et al. (2012) AoA & $4.968(.81)$ & $9.997(.77)^{* * *}$ \\
Log frequency & $2.56(.62)$ & $2.51(.57)$ \\
Length & $6.00(.86)$ & $6.00(.83)$ \\
Familiarity & $6.66(.33)$ & $6.60(.31)$ \\
Imageability & $5.62(1.25)$ & $5.61(1.19)$ \\
OLD-20 & $2.15(.44)$ & $2.30(.47)$ \\
Sentence rating & $6.39(.51)$ & $6.30(.46)$ \\
Cloze probability & $.00(.00)$ & $.00(.00)$ \\
\hline
\end{tabular}

Note. ${ }^{* * *} p<.001$. For all other comparisons, $p>.10$. Numbers in parentheses are standard deviations. Rated AoA, familiarity, imageability, and sentence ratings were on a 1-7 scale. Sentence rating is a measure of how well the target word fits in the sentence context. Kuperman et al. (2012) AoA is in years. Log frequency was taken from the Subtlex-US corpus (Brysbaert \& New, 2009) from the English Lexicon Project (Balota et al., 2007). OLD-20, the orthographic Levenschtein distance, was obtained from the English Lexicon Project
Introductory Psychology course or received payment (\$10.00). All participants reported that their primary language was English and had normal or corrected-to-normal vision. Eye-movement data were collected from eight additional participants, but were not included in the analysis due to excessive track losses (over 30\%), low accuracy to comprehension questions ( $60 \%$ or below), or technical issues with the host computer. The current sample size is larger than others that have explored the effects of AoA on eye-fixation durations (see Table 1). ${ }^{1}$

\section{Apparatus}

An EyeLink 1000 (SR Research, Ltd.) eye tracker was used to record eye movements as participants read sentences on a computer screen located 75 centimeters away. This system records eye movements every millisecond, with high spatial resolution. While eye movements were only recorded from the right eye, participants viewed the sentences binocularly. The experiment was programmed using the Experiment Builder program (SR Research, LTD). The sentences were presented in black on a white background using a monospaced Courier New font, where approximately 4.36 characters were equivalent to one degree of visual angle. All of the sentences were displayed on a single line of text.

\section{Materials}

A set of 722 items were selected from the Kuperman, Stadthagen-Gonzalez, and Brysbaert (2012) database of AoA ratings for local norming. These words were included on questionnaires assessing their rated AoA (1-7 Gilhooly \& Logie, 1980, scale where $1=$ the word was learned at ages 0 2 , and $7=$ the word was learned at age 13 or older), familiarity and imageability (both on a 1-7 scale, where higher numbers indicate greater familiarity and imageability). Seventy Wesleyan University undergraduates rated the items, with each item being rated by between 11-13 individuals. A final set of 100 words (50 early AoA and 50 late AoA) was selected from these ratings.

Some researchers have questioned the accuracy of adult AoA ratings (see, e.g., Wikse Barrow, Björkenstam, \& Strömbergsson, 2019). However, Brysbaert (2017) has recently

\footnotetext{
${ }^{1}$ Brysbaert and Stevens (2018) have recently recommended that psycholinguistic experiments with repeated measures should ensure at least 1,600 observations per condition for adequate statistical power. With 50 items per AoA condition, a sample size of 32 participants would be required to achieve a potential maximum of 1,600 observations per condition. We have a larger sample size (47 participants), to allow for a potential maximum of 2,350 observations per AoA condition. Given the nature of eye-movement recording, both track losses and skipping of the target word reduce the number of usable observations (see the Data Analysis section). Thus, by using as sample size of 47 participants, we are able to ensure that there are a larger number of observations than the recommended 1,600 observations per condition.
} 
shown that rated AoA demonstrates the best criterion validity with objective measures of when a word is first learned. In the present study, we ensured that our early and late AoA items had non-overlapping distributions of ratings in both the Kuperman et al. (2012) database (which was collected from a large online sample across the United States) and the locally collected norms in order to create a strong manipulation of AoA for our participant group. For the early AoA items the ranges were 2.50-6.00 years in the Kuperman et al. (2012) database and 1.82-3.64 (out of 7) for the local norms. For the late AoA items the ranges were 9.00-12.24 years for the Kuperman et al. (2012) database and 3.82-6.45 (out of 7) for the local norms.

Pairs of early and late AoA words were matched on a number of lexical and semantic variables (see Table 2). Two sentence frames were written for each pair such that the context was the same through at least the posttarget word. The target word was never the first or last two words in the sentence. Ratings were collected on how well each word fit into their sentence context (1-7 scale). Each participant rated every target word in a different sentence frame. Target predictability was assessed via a modified cloze questionnaire. Based on the sentence norming, a subset of sentences were rewritten and new ratings were collected. A total of 52 Wesleyan University undergraduates rated these sentences, with each sentence being rated by between eight and 10 individuals. Example items and sentences are provided in Table 3. A full list of experimental sentences is contained in the Appendix.

\section{Procedure}

After instructions, participants were calibrated, and sentences were only displayed if the average calibration

Table 3 Example sentences from the experiment

\begin{tabular}{|c|c|}
\hline Condition & Sentence \\
\hline Early AoA & $\begin{array}{l}\text { Lucy aspired to become a successful dentist } \\
\text { after finishing college. } \\
\text { Jennifer made a trip to see the local dentist } \\
\text { when her teeth began to hurt. }\end{array}$ \\
\hline Late AoA & $\begin{array}{l}\text { Lucy aspired to become a successful senator } \\
\text { after finishing law school. } \\
\text { Jennifer made a trip to see the local senator } \\
\text { when she was writing her article. }\end{array}$ \\
\hline Early AoA & $\begin{array}{l}\text { Julia will go to the mall to buy a new skirt } \\
\text { when she gets out of work. } \\
\text { Meghan thought that the purple skirt would } \\
\text { look great with her shoes. }\end{array}$ \\
\hline Late AoA & $\begin{array}{l}\text { Julia will go to the mall to buy a new shawl } \\
\text { when she gets out of work. } \\
\text { Meghan thought that the purple shawl would } \\
\text { be perfect for her mom. }\end{array}$ \\
\hline
\end{tabular}

Note. Target words are presented in bold in the sentences here, but were not bolded during the experiment error was .4 degrees of visual angle or less. The experimenter was present in the room during the experiment, and controlled the display of each sentence and conducted recalibrations when necessary. Prior to each sentence, participants fixated on a circle on the left side of the screen to check the calibration. Participants were instructed to silently read the sentences for meaning and press a button to terminate the trial. In addition to the 100 experimental sentences, 40 filler sentences were also included in the session (five of which were used as practice), for a total of 140 sentences. The order of the sentences was randomized. Two experimental lists were prepared such that each participant read every target word once, and the assignment of the target words to sentence frames was counterbalanced across participants. Comprehension was checked via yes-no comprehension questions on $25 \%$ of the sentences. Average accuracy was $94.77 \%$.

\section{Data analysis}

Eye movements were inspected using the DataViewer software (SR Research LTD) and trials were removed from the analysis for track losses on the pretarget, target, or posttarget word or if the initial fixation on the sentence was not on the first region. This led to the removal of $5.43 \%$ of the trials. The target word was also skipped on some trials (see Table 4). For firstfixation durations, there were 1,982 observations remaining for the early AoA condition and 2,015 observations remaining for the late AoA condition. An analysis on the number of observations per item demonstrated that these two conditions did not differ significantly from each other, $t_{2}(49)=-1.55, p=.127$. Initial analyses focused on the mean differences between early and late AoA items on fixation duration measures and skipping rates used paired-sample $t$ tests computed both by participants $\left(t_{1}\right)$ and by items $\left(t_{2}\right)$. Next, we estimated the earliest discernable effect of AoA on distributions of first-fixation durations, using both survival analyses (Reingold \& Sheridan, 2014, 2018) and Vincentile analyses (Ratcliff, 1979; Vincent, 1912). ${ }^{2}$

\footnotetext{
${ }^{2}$ In addition, to further explore the effect of AoA on distributions of fixations, we conducted a $2 \times 10$ repeated-measures ANOVA, with age of acquisition and Vincentile bin as within-subjects variables. We used the GreenhouseGeisser epsilon correction for violation of sphericity. There was a main effect of AoA, $F(1,46)=13.04, p<.01$, and no interaction, $F(1.86,85.61)=1.60, p$ $=.209$. The lack of an interaction suggests that AoA effects are relatively consistent in magnitude across the distribution. However, future work could further explore if the magnitude of AoA effects varies across the distribution by employing other distributional analysis techniques, such as ex-Gaussian fitting. In the present study, only $68 \%$ of participants (i.e., 32 out of 47 ) met the recommended minimum of 40 observations per condition to perform exGaussian fitting using QMPE (Cousineau, Brown, \& Heathcote, 2004; Heathcote, Brown, \& Mewhort, 2002).
} 
Table 4 By participant means (in ms) for early and late AoA conditions and statistical results

\begin{tabular}{|c|c|c|c|}
\hline Measure & Early AoA & Late AoA & $t$ test results \\
\hline First fixation & $239(5.20)$ & $247(5.40)$ & $\begin{array}{l}t_{1}(46)=3.70, p=.001, d=.22 \\
t_{2}(49)=2.30, p=.026, d=.42\end{array}$ \\
\hline Single fixation & $242(5.51)$ & $251(5.95)$ & $\begin{array}{l}t_{1}(46)=3.36, p=.009, d=.20 \\
t_{2}(49)=2.22, p=.031, d=.39\end{array}$ \\
\hline Gaze duration & $260(6.50)$ & $269(6.94)$ & $\begin{array}{l}t_{1}(46)=2.74, p=.009, d=.20 \\
t_{2}(49)=1.98, p=.053, d=.35\end{array}$ \\
\hline Total time & $291(8.57)$ & $307(8.66)$ & $\begin{array}{l}t_{1}(46)=3.94, p<.001, d=.27 \\
t_{2}(49)=2.15, p=.036, d=.41\end{array}$ \\
\hline Skipping percentage & $10.94(1.54)$ & $9.29(1.19)$ & $\begin{array}{l}t_{1}(46)=1.68, p=.100, d=.17 \\
t_{2}(49)=1.99, p=.052, d=.34\end{array}$ \\
\hline
\end{tabular}

Note. Numbers in parentheses are the standard error (SE) of the means. The means and SEs shown above are based on the by-participant analyses

\section{Results}

Results from an initial examination of the mean AoA effect on four fixation duration measures (first-fixation duration, singlefixation duration, gaze duration, and total-fixation duration) and skipping rates are displayed in Table 4. As can be observed, early acquired words received shorter fixation durations compared with later acquired words on all fixation duration measures. Skipping rates, while not significant, were in the expected direction (with early AoA items skipped a slightly higher percentage of the time relative to late AoA items).

The main focus of the study was to examine first-fixation duration distributions for the early and late AoA items. These are presented in Fig. 1. For each participant and condition, we calculated the proportion of first-fixation durations that fell within each successive $25-\mathrm{ms}$ bin in the range from $0 \mathrm{~ms}$ to $600 \mathrm{~ms}$. These values were then averaged to create histograms (see Fig. 1a). As shown in this figure, the distribution of late AoA fixations appears to be shifted to the right of the early AoA distribution. To estimate the point at which the late and early AoA distributions first began to show discernable differences (i.e., the divergence point), we used a survival analysis technique (see Fig. 1b). Specifically, we contrasted the survival curves of first-fixation durations across the two AoA conditions using a bootstrap resampling procedure (see Reingold $\&$ Sheridan, 2014). We used the confidence interval version of the DPA procedure described by Reingold et al. (2014), which yielded a divergence-point estimate of $158 \mathrm{~ms}$ (upper bound = 166 and lower bound $=135){ }^{3}$

To further explore the impact of the AoA variable on the first-fixation distributions, we also conducted Vincentile

\footnotetext{
${ }^{3}$ As recommend by Reingold and Sheridan (2018), we also analyzed our data set using the Original-DPA procedure (as an extra verification step), and this procedure yielded a divergence point at $167 \mathrm{~ms}$. We are focusing on the CIDPA procedure in the text because it provides confidence intervals that facilitate comparisons across data sets (for further discussion, see Reingold \& Sheridan, 2014, 2018).
}

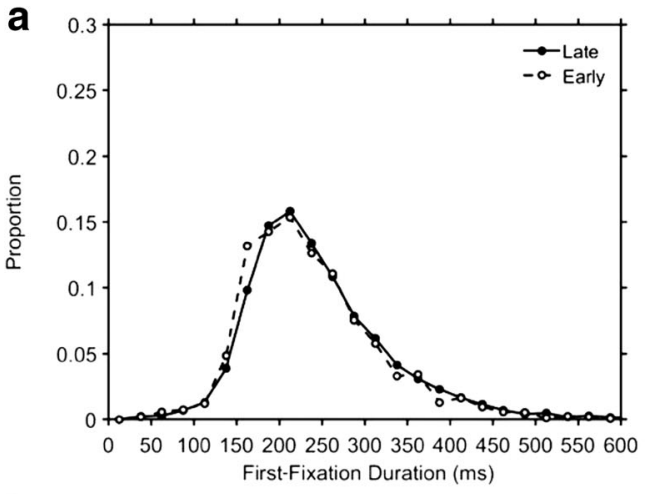

b
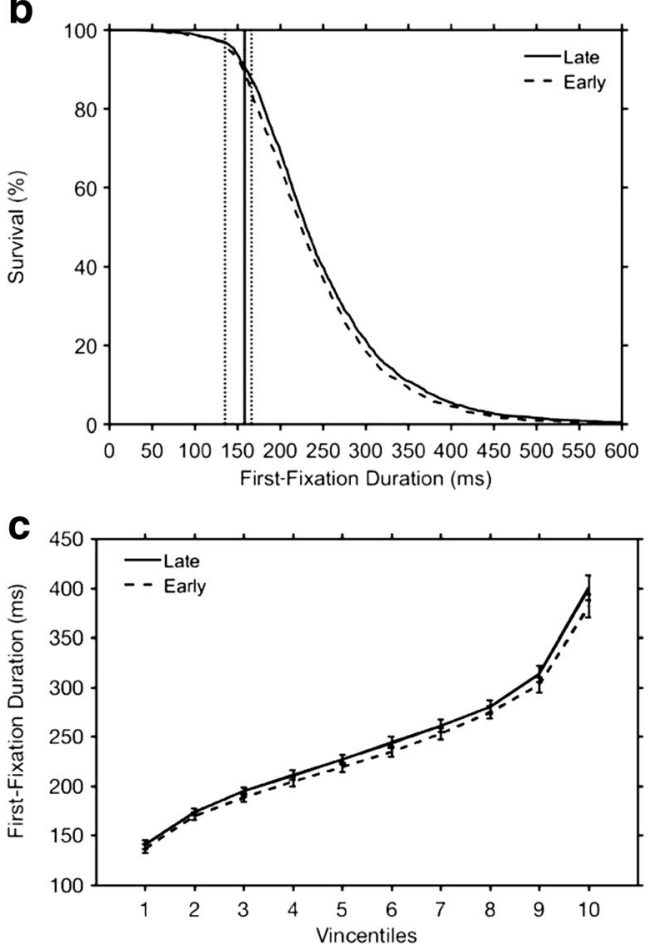

Fig. 1 Distributions of first-fixation durations on early and late acquired target words (a), and survival curves (b), and Vincentile plots (c) that were generated from these distributions. See text for details 
analyses (see Fig. 1c). As can be seen from this figure, the AoA effect emerged early and was relatively consistent in magnitude across the distribution. We conducted $t$ tests to compare the early and late conditions for each individual bin. As shown in Table 5, a wide range of bins produced significant differences, with significant effects first emerging for the third bin, $t(46)=2.91, p=.005 . d=.26$, although the second bin was approaching significance, $t(46)=1.88, p=$ $.067, d=.16$. The Vincentile analyses are therefore consistent with the early divergence points from the survival analyses and suggest that the AoA effect persists across a wide range of fixation durations.

\section{Discussion}

The purpose of this study was to further examine the time course of AoA effects during reading. AoA effects were observed in four fixation-duration measures, providing converging support that AoA has an early and lasting influence on the eye-movement record. The current study provides a strong test of the AoA effect on fixation durations, as it includes data from a larger number of participants compared with most past studies (see Table 1). In addition, the number of items per AoA condition was also larger in the current study (50 items) relative to past factorial investigations of AoA effects on the eye-movement record (Cushman \& Johnson, 2011 - 20 items; Juhasz \& Rayner, 2006-36 and nine items in Experiments 1 and 2, respectively). It should be noted that the size of the AoA effect was reduced in gaze durations and total fixation durations (9 ms and $16 \mathrm{~ms}$, respectively) compared with the past eye-movement studies with younger adults (e.g., Dirix \& Duyck, 2017a; Juhasz \& Rayner, 2006). This reduction could be because the current study controlled the early and later

Table 5 Statistical results and early and late AoA condition firstfixation means by Vincentile bin

\begin{tabular}{llll} 
Vincentile Bin & Early AoA & Late AoA & $t$ test results \\
\hline 1 & $137(4.3)$ & $141(4.1)$ & $t(46)=1.53, p=.133, d=.14$ \\
2 & $169(3.8)$ & $173(3.4)$ & $t(46)=1.88, p=.067, d=.16$ \\
3 & $\mathbf{1 8 8 ( 4 . 1 )}$ & $\mathbf{1 9 5 ( 3 . 8 )}$ & $\boldsymbol{t}(\mathbf{4 6})=\mathbf{2 . 9 1}, \boldsymbol{p}=\mathbf{. 0 0 5}, \boldsymbol{d}=\mathbf{. 2 6}$ \\
4 & $\mathbf{2 0 4 ( 4 . 6 )}$ & $\mathbf{2 1 1 ( 4 . 6 )}$ & $\boldsymbol{t}(\mathbf{4 6})=\mathbf{2 . 8 8 ,} \boldsymbol{p}=\mathbf{. 0 0 6}, \boldsymbol{d}=\mathbf{. 2 2}$ \\
5 & $\mathbf{2 1 9 ( 5 . 0 )}$ & $\mathbf{2 2 7 ( 5 . 1 )}$ & $\boldsymbol{t}(\mathbf{4 6})=\mathbf{3 . 0 4}, \boldsymbol{p}=\mathbf{. 0 0 4}, \boldsymbol{d}=\mathbf{. 2 3}$ \\
6 & $\mathbf{2 3 4 ( 5 . 2 )}$ & $\mathbf{2 4 4 ( 5 . 5 )}$ & $\boldsymbol{t}(\mathbf{4 6})=\mathbf{3 . 4 7} \boldsymbol{p}=\mathbf{. 0 0 1} \boldsymbol{d}=\mathbf{. 2 7}$ \\
7 & $\mathbf{2 5 3 ( 5 . 7 )}$ & $\mathbf{2 6 1 ( 6 . 1 )}$ & $\boldsymbol{t}(\mathbf{4 6})=\mathbf{2 . 8 8}, \boldsymbol{p}=\mathbf{. 0 0 6}, \boldsymbol{d}=. \mathbf{2 0}$ \\
8 & $275(6.5)$ & $280(6.6)$ & $t(46)=1.80, p=.078, d=.11$ \\
9 & $302(7.6)$ & $313(8.0)$ & $t(46)=2.61, p=.012, d=.21$ \\
10 & $381(11.5)$ & $400(12.6)$ & $t(46)=2.03, p=.048, d=.23$ \\
\hline
\end{tabular}

Note. The Vincentile bins shown in bold were statistically significant after we applied the Bonferroni-Holm correction for multiple comparisons to maintain an overall alpha of .05 (Holm, 1979) acquired items on a larger number of lexical variables compared with these past studies. The current analyses therefore support an effect of AoA on fixation durations once a number of other correlated lexical and semantic factors are controlled. These analyses also suggest an early role for AoA in the eyemovement record. AoA exerts its influence on first-fixation durations, and the magnitude of the effect is relatively consistent across the eye-movement record.

The main contribution of the present study was the use of distributional analyses to explore the time course of AoA effects on first-fixation distributions. Specifically, survival analyses showed that the earliest discernable impact of AoA on first-fixation distributions emerged beginning at $158 \mathrm{~ms}$ (see Fig. 1b), and Vincentile analyses showed an early and relatively stable impact of AoA across first-fixation durations (see Fig. 1c). These findings build on prior results showing that other lexical variables produce a rapid impact on fixation duration distributions, including word frequency, predictability, and lexical ambiguity (for a review, see Reingold et al., 2015).

The rapid influence of AoA (as well as other lexical variables) on first-fixation distributions is consistent with the direct lexical-control hypothesis, which assumes that the lexical and linguistic properties of the word being fixated can have a rapid impact on fixation durations. The direct lexical-control hypothesis stands in contrast to the viewpoint that lexical and linguistic variables have a more minimal influence that is largely driven by longer fixation durations. Several leading models of eye-movement control during reading have adopted mechanisms that permit direct lexical control, including the EZ Reader model (Reichle, Pollatsek, Fisher, \& Rayner, 1998; Reichle et al., 2012), which assumes that the completion of an early stage of lexical processing triggers the initiation of saccadic programming, and the SWIFT model (Engbert, Longtin, \& Kliegl, 2002; Engbert, Nuthmann, Richter, \& Kliegl, 2005), which assumes that lexical processing difficulty can inhibit the programming of saccades. The examination of lexical effects on distributions (in addition to mean analyses) can provide empirical constraints to inform future model development.

In addition, the current finding of a rapid effect of AoA on the eye-movement record is informative for theories of AoA effects, especially given that prior evidence concerning the time course of AoA effects during reading has been mixed (see Table 1). We interpret our results as being consistent with the network plasticity hypothesis of AoA effects (Ellis \& Lambon Ralph, 2000), which ascribes AoA effects to multiple levels in the mental lexicon. The rapid impact of AoA on firstfixation durations suggests that an early stage of lexical processing (such as the $L_{1}$ stage of the E-Z Reader model) may be affected by the age (or order) at which a word is first learned. AoA effects could therefore result from a general learning principle related to overall plasticity when early items are first learned that allows faster access to orthographic, 
phonological, and semantic representations for a given word. This is not to say, however, that AoA does not affect semantic organization, as proposed by Steyvers and Tenenbaum (2005). As discussed recently by Dirix and Duyck (2017a), a combination of both network plasticity and organization of the semantic system may plausibly contribute to the observed AoA effects on fixation durations in reading. However, a major contribution of the current study is that it provides clear support for the rapid impact of AoA on the eye-movement record.

Finally, the present findings point to several possible directions for future research. First, given the timing constraints inherent to oculomotor control during reading, parafoveal processing may play an important role in enabling the direct lexical-control of eye movements during reading (for related discussions, see Reichle \& Reingold, 2013; Reingold et al., 2012). Future research could explore whether AoA effects on fixation durations would be affected by the availability of upcoming target words for parafoveal processing. Second, word frequency is clearly a complex variable, and it is an open question how this variable would affect fixation durations if a variety of potentially confounding variables (such as AoA) were controlled for. Here, we show that the AoA variable can rapidly affect first-fixation duration distributions under natural reading conditions, while controlling for potentially confounding lexical variables, such as word frequency and predictability.

Author note This research was supported by a Wesleyan University project grant. We would like to thank Eyal Reingold for discussions during planning stages of the project and the undergraduate research assistants at Wesleyan University who contributed to this project. Portions of the data were presented at the European Conference on Eye Movements in August 2017 and the Psychonomic Society Annual Meeting in November 2017.

Correspondence should be addressed to Barbara J. Juhasz, Department of Psychology, Wesleyan University, Middletown, CT 06459. E-mail: bjuhasz@wesleyan.edu

Open practices statement This experiment was not preregistered. Interested researchers can contact the authors to receive access to the eye-movement data and relevant analyses.

\section{Appendix}

Sentence frames for the early and late AoA items used in the eye-movement experiment. Early and late AoA target words were paired, and each had two sentence frames written that were the same through at least the posttarget word. Two experimental lists were prepared so that each participant read every target word in a different sentence frame. Target words are presented in bold in the sentences here, but were not bolded during the experiment.

\section{Early acquired items-Sentence Frame \#1}

My mother said that even a little acorn will grow into a big oak tree.

I was hoping that the latest apology that the politician gave would be sincere.

You could barely see the hidden beetle beneath the bricks on the wall.

Jack headed to the nearest bench when he needed to take a long rest.

Jessica spotted the dark branch before she collided with it.

I admired the beautiful cartoon that covered up the graffiti on the wall.

Layla had to decide which choice would be best by the end of the day.

Clara thought that the only chore worth doing was cleaning her room.

Going to the noisy circus gave Lauren a severe headache for two days.

John enjoyed being in the large class surrounded by his many peers.

Marsha thought the old costume smelled like sweat from all the performances.

Martin grabbed the last crayon before anyone else could get it.

Chris decided to purchase the new cushion since the old one was all ripped.

Lucy aspired to become a successful dentist after finishing college.

Caroline had the best dessert with her pasta dinner tonight.

Jacqueline really hated the annoying freckle that she had on her nose.

Brian marveled at the baby giraffe slowly walking by at the zoo.

Bella felt that the climbing height was too much for her to continue the hike.

Adam avoided the dark insect crawling down the long hallway.

I rarely ever have juice because of the high amount of sugar in it.

I was glad to see that the updated kitchen included a new dishwasher.

The much needed lullaby helped the baby fall asleep much faster.

I found my grandmother's old mitten when I cleaned out her attic.

In the story, a hidden monster jumps out at the unsuspecting children.

Jennifer disliked the annoying noise coming from her headphones. 
Michelle looked at the only noodle that was left floating in the soup.

Our goal is to support every parent when they need some help.

Stephanie interviewed a potential partner before hiring her.

He learned that Sarah prefers pasta over stir fry for dinner.

I was excited to go to the outdoor picnic where I would see all my friends.

Tracy was proud of the new prize given to her for her artwork.

At first I did not notice the massive puddle blocking my pathway.

This restaurant is famous for their delicious sauce served with all dishes.

Maria won a free shampoo from her hairdresser the last time she went.

The student looked at the detailed sheet that instructed him what to do.

The worker fixed the broken shelf carefully to avoid splinters.

Julia will go to the mall to buy a new skirt when she gets out of work.

Marcus sat on the large sleigh and took pictures with Santa. I just saw a tiny snail that was sitting on a leaf in a bush.

Some people believe that spinach increases their physical abilities.

Mark dropped the large spoon down into the bottom of the pot.

Nancy was rewarded with a fancy sticker after enduring the dentist.

I tried to fix the defective strap that broke on my new purse.

Connor watched the new student complete the equation correctly.

You cannot substitute the plain syrup with any other flavor in the recipe.

Apparently, the most recent thunder was the loudest on record.

Julie misunderstood the simple truth involved in the decision process.

Kara thought that the yucky vitamin tasted awful so she spit it out.

The man towed his new wagon behind him as he headed to the store.

Jackson greatly preferred yogurt compared with any other foods.

\section{Early acquired items-Sentence Frame \#2}

Maria put a little acorn into the pocket of her jeans to bring home.
Billy said that the real apology was going to be made in the press conference.

Tara saw the ugly beetle when she stepped outside of her dorm room.

Meet me at that bench near the park after you finish your run.

I was surprised when the small branch outside was infested with little bugs.

Wanda told me about the colorful cartoon she had drawn for art class.

Max accepted the difficult choice hoping he would learn more from it.

Therese told me that the last chore she did was washing the floor.

We went to the famous circus when it came to town last fall.

I went to an amazing class during my visit to the local college.

I packed up my mother's costume after the amazing Halloween party.

Peter got another crayon from the box to give to his sister.

I was happy that the expensive cushion was on sale for such a reasonable price.

Jennifer made a trip to see the local dentist when her teeth began to hurt.

Tina thought that the massive dessert tasted delicious after the small meal.

Jillian could see the large freckle just above her shirt collar.

I watched the mother giraffe feed her baby when I went to the zoo.

Barb thought that the incredible height would be too much for her mom to climb.

Chris thought that the large insect really was quite frightening to see.

The store did not carry the cheap juice that my children prefer to drink.

Jasmine thought that the old kitchen definitely needed repairs.

Sophia created a unique lullaby just for her youngest niece.

Miranda thought that the white mitten would get dirty much too quickly.

Miles thought that the dreadful monster would be great for the haunted house.

Tara thought that the unusual noise coming from her computer was strange.

Cathy accidentally dropped the last noodle onto the dirty kitchen floor.

There was a very helpful parent organizing the fundraiser for the school.

Catherine and her new partner worked extremely well together.

I've never met someone who enjoys pasta quite as much as Lilly. 
Jenny thought that an indoor picnic would be great fun for her kids.

We developed a respected prize that was given out to an author every year.

Jack stood by the wide puddle trying to determine how to get around it.

I thought that the spicy sauce could have been much better.

Colin bought his wife an expensive shampoo from her favorite salon.

Billy went to get the updated sheet with the answers from his teacher.

Mike bought a small shelf yesterday to install in his new apartment.

Meghan thought that the purple skirt would look great with her shoes.

Josh decided to build a wooden sleigh for a Christmas decoration.

Tara drew a picture of a brown snail during her art class yesterday.

Micaela put some extra spinach into the yummy artichoke dip.

Kate brought her own spoon since she did not like using dirty utensils.

Julia carefully put her new sticker into the book she had purchased.

Paul thought that the broken strap could be fixed on his computer bag.

I welcomed the new student during her first class of the day.

I mistakenly used syrup instead of vanilla extract while baking a cake.

I could not believe that last night's thunder could be heard so far away.

I struggled to interpret the complex truth involved in the situation.

Becky took Bob's vitamin before she realized it was not hers.

Rob decided to build a large wagon during the year for his final course project.

Having a little yogurt occasionally for lunch is a nice treat to cheer me up.

\section{Late acquired items-Sentence Frame \#1}

My mother said that even a little basil will add so much flavor to the dish.

I was hoping that the latest tragedy that I heard on the news would be the last.

You could barely see the hidden pimple beneath the makeup on her face.

Jack headed to the nearest clinic when he needed to see a doctor.
Jessica spotted the dark orchid before any of the bright flowers.

I admired the beautiful foliage that covered the forest on our hike.

Layla had to decide which career would be best for her future success.

Clara thought that the only stock worth buying was Amazon's.

Going to the noisy casino gave Lauren a severe headache for two days.

John enjoyed being in the large plaza surrounded by pigeons and other birds.

Marsha thought the old estate smelled like mold so she left very quickly.

Martin grabbed the last martini before he headed home from the party.

Chris decided to purchase the new granite since he was replacing his counter.

Lucy aspired to become a successful senator after finishing law school.

Caroline had the best avocado with her quesadilla at the restaurant.

Jacqueline really hated the annoying mascot that ran up and down the room.

Brian marveled at the baby gazelle slowly walking by at the zoo.

Bella felt that the climbing expert was a great help during the hike.

Adam avoided the dark saloon crawling with unsavory people.

I rarely ever have booze because of the poor effects it has on my health.

I was glad to see that the updated brewery included a new tasting room.

The much needed formula helped the baby fall asleep much faster.

I found my grandmother's old corset when I cleaned out her attic.

In the story, a hidden corpse jumps out at the unsuspecting children.

Jennifer disliked the annoying audio coming from her headphones.

Michelle looked at the only grenade that was left in the bunker

Our goal is to support every veteran when they need some help.

Stephanie interviewed a potential client before agreeing to work with him.

He learned that Sarah prefers disco over jazz for dancing.

I was excited to go to the outdoor arena where I would see my favorite team.

Tracy was proud of the new union given how hard it was to form. 
At first I did not notice the massive podium blocking my view of the stage.

This restaurant is famous for their delicious sushi served with wasabi.

Maria won a free massage from the spa the last time she went.

The student looked at the detailed script that instructed him what to do.

The worker fixed the broken cable carefully to avoid cutting other wires.

Julia will go to the mall to buy a new shawl when she gets out of work.

Marcus sat on the large ledge and looked at the ground below.

I just saw a tiny gecko that was sitting on a leaf in a bush.

Some people believe that whiskey increases their physical abilities.

Mark dropped the large ladle down into the bottom of the pot.

Nancy was rewarded with a fancy diploma after finishing college.

I tried to fix the defective radar that I purchased for my boat.

Connor watched the new manager complete all her tasks efficiently.

You cannot substitute the plain vodka with a flavored one in the drink.

Apparently, the most recent lottery was the largest on record.

Julie misunderstood the simple system involved in making the program work.

Kara thought that the yucky alcohol tasted awful so she spit it out.

The man towed his new yacht behind his truck as he headed to the docks.

Jackson greatly preferred luxury compared with living life simply.

\section{Late acquired items-Sentence Frame \#2}

Maria put a little basil into her famous lasagna as the secret ingredient.

Billy said that the real tragedy was that the children could not be reunited.

Tara saw the ugly pimple when she looked in the mirror this morning.

Meet me at that clinic near the mall when you get out of work.

I was surprised when the small orchid outside was infested with little bugs.

Wanda told me about the colorful foliage she had seen on her trip.
Max accepted the difficult career hoping he would make more money.

Therese told me that the last stock she bought was Microsoft's

We went to the famous casino when we took a trip to Las Vegas.

I went to an amazing plaza during my trip to the southeast of Italy.

I packed up my mother's estate after we had to move her to a nursing home.

Peter got another martini from the bartender for his friend.

I was happy that the expensive granite was on sale for such a reasonable price.

Jennifer made a trip to see the local senator when she was writing her article.

Tina thought that the massive avocado tasted like it was over ripe.

Jillian could see the large mascot just about to run around the stadium.

I watched the mother gazelle feed her baby when I went to the zoo.

Barb thought that the incredible expert would be able to help them decide.

Chris thought that the large saloon really was a fun tourist attraction.

The store did not carry the cheap booze that my friends wanted to buy.

Jasmine thought that the old brewery definitely needed a renovation.

Sophia created a unique formula just to accommodate for the new findings.

Miranda thought that the white corset would be perfect for her costume.

Miles thought that the dreadful corpse would be great for the haunted house.

Tara thought that the unusual audio coming from her computer was strange.

Cathy accidentally dropped the last grenade onto the pile of explosives.

There was a very helpful veteran organizing the information session.

Catherine and her new client worked extremely well together.

I've never met someone who enjoys disco quite as much as Lilly.

Jenny thought that an indoor arena would be a great place for the event.

We developed a respected union that fought hard for worker's rights.

Jack stood by the wide podium trying to remember the important speech.

I thought that the spicy sushi could have been much better. 
Colin bought his wife an expensive massage from her favorite masseuse.

Billy went to get the updated script with the new lines he would have to learn.

Mike bought a small cable yesterday to connect his computer and monitor.

Meghan thought that the purple shawl would be perfect for her mom.

Josh decided to build a wooden ledge for the local skate park.

Tara drew a picture of a brown gecko during her art class yesterday.

Micaela put some extra whiskey into the drink for her husband.

Kate brought her own ladle since she was not sure if Larry had one.

Julia carefully put her new diploma into the frame she had purchased.

Paul thought that the broken radar could be fixed relatively easily.

I welcomed the new manager during our staff meeting this morning.

I mistakenly used vodka instead of rum in my mixed drink last night.

I could not believe that last night's lottery could be won by so many people.

I struggled to interpret the complex system involved in analyzing the data.

Becky took Bob's alcohol before he could take another drink.

Rob decided to build a large yacht during his retirement so he could live on it.

Having a little luxury occasionally is important to stay rejuvenated.

\section{References}

Balota, D. A., \& Yap, M. J. (2011). Moving beyond the mean in studies of mental chronometry: The power of response time distributional analyses. Current Directions in Psychological Science, 20, 160166.

Balota, D. A., Yap, M. J., Hutchison, K. A., Cortese, M. J., Kessler, B., Loftis, B., Neely, J.H., Nelson, D.L., Simpson, G.B., \& Treiman, R. (2007). The English Lexicon Project. Behavior Research Methods, $39,445-459$.

Brysbaert, M. (2017). Age of acquisition ratings score better on criterion validity than frequency trajectory or ratings "corrected" for frequency. The Quarterly Journal of Experimental Psychology, 70, 11291139.

Brysbaert, M., \& Cortese, M. J. (2011). Do the effects of subjective frequency and age of acquisition survive better word frequency norms? The Quarterly Journal of Experimental Psychology, 64, $545-559$.

Brysbaert, M., \& New, B. (2009). Moving beyond Kučera and Francis: A critical evaluation of current word frequency norms and the introduction of a new and improved word frequency measure for American English. Behavior Research Methods, 41, 977-990.

Brysbaert, M., \& Stevens, M. (2018). Power analysis and effect size in mixed effects models: A tutorial. Journal of Cognition, 1, 1-20.

Cousineau, D., Brown, S., \& Heathcote, A. (2004). Fitting distributions using maximum likelihood: Methods and packages. Behavior Research Methods, Instruments, \& Computers, 36, 742-756.

Cushman, C. L., \& Johnson, R. L. (2011). Age-of-acquisition effects in pure alexia. The Quarterly Journal of Experimental Psychology, 64, $1726-1742$.

Dirix, N., \& Duyck, W. (2017a). An eye movement corpus analysis of the age-of-acquisition effect. Psychonomic Bulletin \& Review, 24, 1915-1921.

Dirix, N. \& Duyck, W. (2017b). The first- and second-language age of acquisition effect in first- and second-language book reading. Journal of Memory and Language, 97, 103-120.

Ellis, A. W., \& Lambon Ralph, M. A. (2000). Age of acquisition effects in adult lexical processing reflect loss of plasticity in maturing systems: Insights from connectionist networks. Journal of Experimental Psychology: Learning, Memory, and Cognition, 26, 1103-1123.

Engbert, R., Longtin, A., \& Kliegl, R. (2002). A dynamical model of saccade generation in reading based on spatially distributed lexical processing. Vision Research, 42(5), 621-636.

Engbert, R., Nuthmann, A., Richter, E. M., \& Kliegl, R. (2005). SWIFT: A dynamical model of saccade generation during reading. Psychological Review, 112(4), 777-813. doi:https://doi.org/10. 1037/0033-295X.112.4.777

Ghyselinck, M., Custers, R., \& Brysbaert, M. (2004). The effect of age of acquisition in visual word processing: Further evidence for the semantic hypothesis. Journal of Experimental Psychology: Learning, Memory, and Cognition, 30, 550-554.

Gilhooly, K. J., \& Logie, R. H. (1980). Age-of-acquisition, imagery, concreteness, familiarity, and ambiguity measures for 1,944 words. Behavior Research Methods and Instrumentation, 12, 395-427.

Heathcote, A., Brown, S., \& Mewhort, D. J. K. (2002). Quantile maximum likelihood estimation of response time distributions. Psychonomic Bulletin \& Review, 9, 394-401.

Holm, S. (1979). A simple sequentially rejective multiple test procedure. Scandinavian Journal of Statistics, 6, 65-70.

Johnston, R. A., \& Barry, C. (2006). Age of acquisition and lexical processing. Visual Cognition, 13, 789-845.

Joseph, H. S. S. L, Wonnacott, E., Forbes, P., \& Nation, K. (2014). Becoming a written word: Eye movements reveal order of acquisition effects following incidental exposure to new words during silent reading. Cognition, 133, 238-248.

Juhasz, B. J. (2005). Age-of-acquisition effects in word and picture identification. Psychological Bulletin, 131, 684-712.

Juhasz, B. J. (2018). Experience with compound words influences their processing: An eye movement investigation with English compound words. Quarterly Journal of Experimental Psychology, 71, 103112.

Juhasz, B. J., Gullick, M. M., \& Shesler, L. W. (2011). The effects of ageof-acquisition on ambiguity resolution: Evidence from eye movements. Journal of Eye Movement Research, 4, 1-14.

Juhasz, B. J., \& Rayner, K. (2003). Investigating the effects of a set of intercorrelated variables on eye fixation durations in reading. Journal of Experimental Psychology: Learning, Memory and Cognition, 29, 1312-1318.

Juhasz, B. J., \& Rayner, K. (2006). The role of age-of-acquisition and word frequency in reading: Evidence from eye fixation durations. Visual Cognition, 13, 846-863.

Kuperman, V., Stadthagen-Gonzalez, H., \& Brysbaert, M. (2012). Ageof-acquisition ratings for 30,000 English words. Behavior Research Methods, 44, 978-990. 
Ratcliff, R. (1979). Group reaction time distributions and an analysis of distribution statistics. Psychological Bulletin, 86(3), 446-461. doi: https://doi.org/10.1037/0033-2909.86.3.446

Rayner, K. (2009). Eye movements and attention in reading, scene perception, and visual search. Quarterly Journal of Experimental Psychology, 62(8), 1457-1506. doi:https://doi.org/10.1080/ 17470210902816461

Reichle, E.D., Pollatsek, A., Fisher, D. L., \& Rayner, K. (1998). Towards a model of eye movement control in reading. Psychological Review, 105, 125-157.

Reichle, E. D., Pollatsek, A., \& Rayner, K. (2012). Using E-Z Reader to simulate eye movements in nonreading tasks: A unified framework for understanding the eye-mind link. Psychological Review, 119(1), 155-185. doi:https://doi.org/10.1037/a0026473

Reichle, E. D., \& Reingold, E. M. (2013). Neurophysiological constraints on the eye-mind link. Frontiers in Human Neuroscience, 7, 1-6.

Reichle, E. D., Tokowicz, N., Liu, Y., \& Perfetti, C. A. (2011). Testing an assumption of the E-Z Reader of eye-movement control during reading: Using event-related potentials to examine the familiarity check. Psychophysiology, 48, 993-1003.

Reingold, E. M., Reichle, E. D., Glaholt, M. G., \& Sheridan, H. (2012). Direct lexical control of eye movements in reading: Evidence from a survival analysis of fixation durations. Cognitive Psychology, 65, 177-206.

Reingold, E. M., \& Sheridan, H. (2014). Estimating the divergence point: A novel distributional analysis procedure for determining the onset of the influence of experimental variables. Frontiers in Psychology, 5, 1432. doi:https://doi.org/10.3389/fpsyg.2014.01432

Reingold, E. M., \& Sheridan, H. (2018). On using distributional analysis techniques for determining the onset of the influence of experimental variables. Quarterly Journal of Experimental Psychology, 71, 260-271.

Reingold, E. M., Sheridan, H., \& Reichle, E. D. (2015). Direct lexical and nonlexical control of fixation duration in reading. In A. Pollatsek \& R. Treiman (Eds.), The Oxford handbook of reading (pp. 261-276). Oxford, UK: Oxford University Press.
Sheridan, H., \& Reingold, E. M. (2012a). The time course of contextual influences during lexical ambiguity resolution: Evidence from distributional analyses of fixation durations. Memory \& Cognition, 40(7), 1122-1131. doi:https://doi.org/10.3758/s13421-012-0216-2

Sheridan, H., \& Reingold, E. M. (2012b). The time course of predictability effects in reading: Evidence from a survival analysis of fixation durations. Visual Cognition, 20(7), 733-745. doi:https://doi.org/10. $1080 / 13506285.2012 .693548$

Staub, A. (2011). The effect of lexical predictability on distributions of eye fixation durations. Psychonomic Bulletin and Review, 18(2), 371-376. doi:https://doi.org/10.3758/s13423-010-0046-9

Staub, A., White, S. J., Drieghe, D., Hollway, E. C., \& Rayner, K. (2010). Distributional effects of word frequency on eye fixation durations. Journal of Experimental Psychology: Human Perception and Performance, 36(5), 1280-1293. doi:https://doi.org/10.1037/ a0016896

Steyvers, M., \& Tenenbaum, J. B. (2005). The large-scale structure of semantic networks: Statistical analyses and a model of semantic growth. Cognitive Science, 29, 41-78.

Vincent S. B. (1912). The function of the viborissae in the behavior of the white rat. Behavioral Monographs, 1(5).

Wikse Barrow, C., Nilsson Björkenstam, K., \& Strömbergsson, S. (2019). Subjective ratings of age-of-acquisition: Exploring issues of validity and rater reliability. Journal of Child Language, 46, 199-213.

Zeno, S. M., Ivens, S. H., Hillard, R.T., \& Duvvuri, R. (1995). The educator's word frequency guide. Brewster, NJ: Touchstone Applied Science Associates.

Zevin, J. D., \& Seidenberg, M. (2004). Age of acquisition effects in reading aloud: Test of cumulative frequency and frequency trajectory. Memory \& Cognition, 32, 31-38.

Publisher's note Springer Nature remains neutral with regard to jurisdictional claims in published maps and institutional affiliations. 